\title{
Comprensiones asociadas a la conservación patrimonial y la escritura furtiva en el espacio público como signo disonante
}

\author{
Chema Segovia Collado | Econcult, Universitat de València \\ URL de la contribución <www.iaph.es/revistaph/index.php/revistaph/article/view/4883>
}

La ciudad es reflejo de la civilización que la construye y habita. Como depósito cultural, evidencia el modo en que entendemos el mundo y cómo funcionamos como sociedad (Volli 2014). La relación que establecemos con nuestro hábitat es bidireccional: lo hacemos a él y él nos hace. A medida que construimos la ciudad, depositamos significados en ese entorno de vida. Simultáneamente, el paisaje urbano actúa como un potente transmisor de sentidos que moldean el modo en que leemos la realidad y nos proyectamos a nosotros mismos.

Por otro lado, la construcción de una ciudad, como espacio de cruces e intercambios, está hecha de transformaciones antes que de permanencias. La conservación de elementos -ya sean materiales o inmateriales- en un entorno urbano en constante agitación exige una atención y un esfuerzo sostenidos que sólo recientemente empezaron a tenerse en consideración (Bandarin y Van Oers 2012).

La idea moderna de la conservación patrimonial, en un sentido amplio, ha estado sujeta a constante revisión crítica desde que en el siglo XVII comenzase a configurarse (Winter 2012). Una de las principales tomas de conciencia en la definición de una comprensión compleja en este sentido llama a entender que el valor asociado a lo patrimonial no es una cualidad intrínseca de los objetos o los lugares calificados de tal modo (generada mágicamente por su antigüedad, su belleza $u$ otras particularidades propias), sino que los objetos y lugares reconocidos como patrimonio son convertidos en firmezas que tratan de expresar, apuntalar y modelar los valores de una determinada comunidad (Smith 2006).

Aunque el concepto de patrimonio nos remita a la construcción de consensos y de sólidas convicciones com- partidas, el campo en el que éste se desenvuelve suele ser el de la discusión y el embrollo. Por añadidura, en no pocas ocasiones cierto reconocimiento patrimonial no garantiza una aceptación social siquiera mayoritaria. El ámbito del grafiti y el arte urbano hace particularmente palpable esta afirmación por el grado de polarización que a su alrededor establece la opinión pública y por

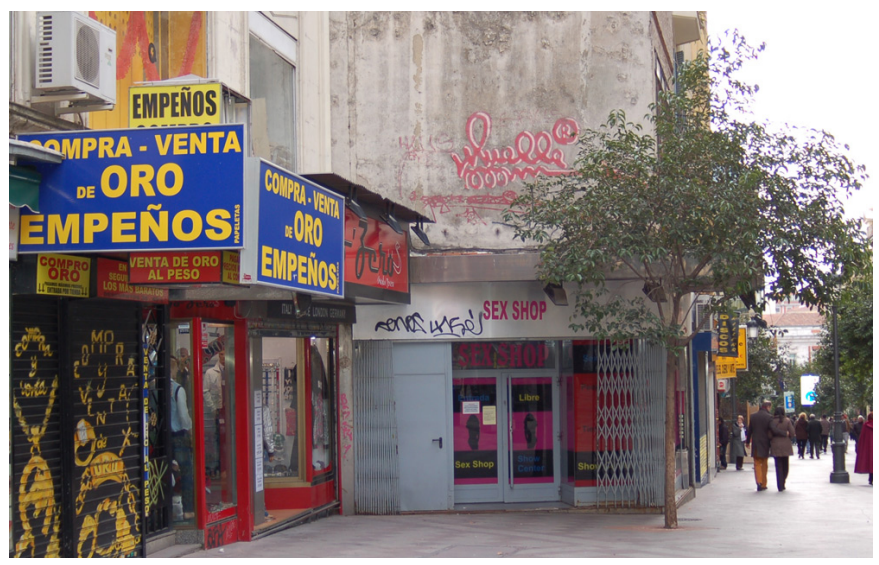

Firma de Muelle restaurada en 2017 | foto Marta Nimeva Nimeviene

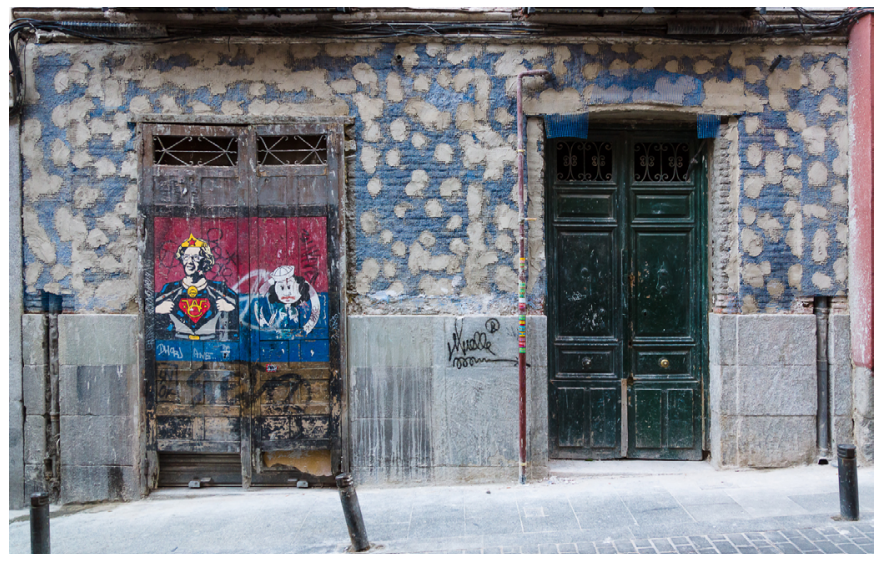

Muelle, firma | foto r2hox 

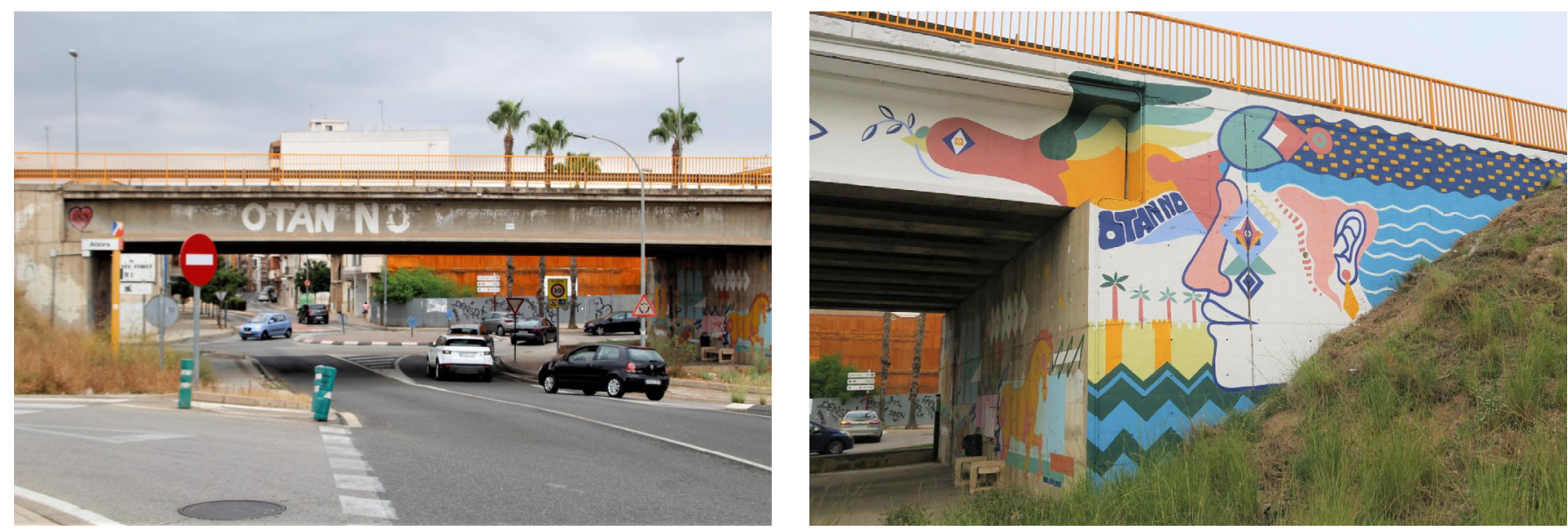

Entrada de Alzira (Valencia). La pintada OTAN NO ha sido sustituida en 2019 por un mural del artista Disneylexya en el que el protagonista es nombre de la ciudad, pero en el que se ha recogido el mensaje precedente | fuente Riberaexpress.es

los contradictorios mensajes que en relación con ambos temas nos envuelven (Evans 2016).

La condición no férrea del patrimonio, lo costoso (e incluso caprichoso) que a veces resulta obtener dicho reconocimiento y el dudoso significado que tal logro puede tener, bien lo expresa el relato detallado del proceso de trabajo que, gracias a la iniciativa y al empeño de un pequeño grupo de personas, concluyó en la restauración y conservación de una firma del grafitero Muelle que desde finales de los 80 sobrevivió en pleno centro de Madrid (Figueroa 2020). El interés del caso Muelle quizá no esté tanto en la brecha que supuestamente abre como en la forma en que nos llama la atención hacia la pared con la que debió confrontarse y el atropellado modo en que logró vencerla.

Otro apunte de valor, aunque la idea de conservación patrimonial nos haga pensar en un pasado recuperado y restaurado, patrimonializar es interpretar (Tunbridge y Ashworth 1996). Es resituar un elemento en nuestro tiempo presente y es darle un nuevo significado. La conservación de la firma de Muelle, por muchos factores casuales que en ella interfirieran, de seguro se vio favorecida por el reencaje que lo contracultural en general y el grafiti en particular han sufrido en el tiempo reciente, hasta convertirse incluso en elementos de proyección de una determinada idea de ciudad (McAuliffe 2012) y, por extensión, de una determinada actitud de gobierno.

La integración del grafiti y del arte urbano en el paisaje urbano se produce en cualquier caso siguiendo un principio por el que nos regimos de manera cada vez más férrea: el intento de evitar cualquier presencia mínimamente perturbadora en el espacio público (Delgado 2011). Para ilustrar esto último, el listado de ejemplos posibles es extenso y hoy día se incrementa con celeridad. Por compartir encuadre de época con la firma de Muelle, y por el contraste que con respecto a ésta introduce, tiene interés hacer mención a la negativa, hace un par de años, del Ayuntamiento de Alzira (València) ante la petición de un grupo ecologista de preservar una pintada contra la OTAN, realizada en uno de los accesos a la ciudad en respuesta a la convocatoria del referéndum de 1986.

En aquel caso, exhibiendo una enorme contradicción interna, los portavoces de un gobierno local de inclinación progresista respondieron a los demandantes: "Estamos, como vosotros, por la paz y las libertades de los pueblos", anunciando que preservarían el recuerdo de la pintada con fotografías y un panel informativo ( $R$. S. 2019). La excusa de la placa conmemorativa sirve para extraer del paisaje urbano la proclama contestata- 
ria, situándola -enjaulándola- en un marco cívico que la atempera y lima sus aristas. El posible desasosiego que pudiese provocar la memoria casi olvidada de la pintada es sustituido por un silencio capaz como ninguna otra cosa de generar unanimidad.

La pintada de OTAN NO despierta en mí el vivo recuerdo infantil de un mensaje similar escrito cerca de la casa donde crecí. La contundencia y el cripticismo de unas mayúsculas trazadas a brocha, que claramente estaban donde no debían estar, captaban fuertemente mi atención de niño. Aquella pintada y comentarios cazados al vuelo de conversaciones entre adultos me hicieron vincular siempre la palabra OTAN a la imagen amenazante de un enorme submarino cargado con bombas nucleares.

La anécdota personal me sirve para cerrar este texto señalando que, a pesar de nuestra perseverancia en generar símbolos que nos aglomeren, un determinado gesto en el paisaje urbano produce generalmente comprensiones subjetivas entre observadores dispares (Evans 2016). La posibilidad de interpelar a la lectura propia se acentúa cuando dicho gesto es furtivo, ambiguo e inarmónico. La pregunta final sería si la posibilidad de dar tratamiento patrimonial al arte urbano y especialmente al grafiti, como prácticas en su raíz discordantes con la concepción hegemónica del espacio público como medio consensuado, regulado, transparente y ordenado, puede vencer sus contradicciones inherentes y servirnos para explorar la posibilidad de relacionarnos con el mundo mediante otro tipo de firmezas: inciertas, incómodas y disonantes.

\section{BIBLIOGRAFÍA}

- Bandarin, F. y Van Oers, R. (2012) The Historic Urban Landscape. Managing Heritage in an Urban Century. Oxford: John Wiley \& Sons

- Delgado, M. (2011) El espacio público como ideología. Madrid: Libros de Catarata

- Figueroa, F. (2020) El reconocimiento cultural del graffiti. El caso Muelle. Ultravandalpro, 16 de junio de 2020. Disponible en: https://www.youtube.com/watch?v=71AV9Fkb7o4 [Consulta: $31 / 03 / 2021]$

- McAuliffe, C. (2012) Graffiti or street art? Negotiating the moral geographies of the creative city. Journal of urban affairs, vol. 34, n. ${ }^{\circ} 2$, pp. $189-206$

- R. S. (2019) ¿Una pintada de hace 40 años contra la OTAN es histórica y debe ser protegida? Levante-El Mercantil Valenciano, 20 de septiembre de 2019. Disponible en: https:// www.levante-emv.com/ribera/2019/09/20/pintada-40-anosotan-historica-11762157.html [Consulta: 31/03/2021]

- Smith, L. (2006) Uses of Heritage. Londres: Routledge

- Tunbridge, J. E. y Ashworth, G. J. (1996) Dissonant Heritage: The management of the past as a resource in conflict. Oxford: John Wiley \& Sons

- Volli, U. (2014) Para una semiótica de la ciudad. Criterios, n. ${ }^{\circ} 61$, pp. $1029-1038$

- Winter, T. (2013) Clarifying the critical in critical heritage studies. International Journal of Heritage Studies, vol. 19, n. ${ }^{\circ} 6$ 